\title{
The Animal Model of Spinal Cord Injury as an Experimental Pain Model
}

\author{
Aya Nakae, ${ }^{1}$ Kunihiro Nakai, ${ }^{2}$ Kenji Yano, ${ }^{2}$ Ko Hosokawa, ${ }^{3}$ Masahiko Shibata, ${ }^{4}$ \\ and Takashi Mashimo ${ }^{1}$ \\ ${ }^{1}$ Department of Anesthesiology \& Intensive Care, Osaka University Graduate School of Medicine, 2-2 Yamadaoka Suita,
Osaka 565-0871, Japan
${ }^{2}$ Department of Breast Regenerative Medicine, Osaka University Graduate School of Medicine, Osaka 565-0871, Japan
${ }^{3}$ Department of Plastic Surgery, Osaka University Graduate School of Medicine, Osaka 565-0871, Japan
${ }^{4}$ Department of Pain Medicine, Osaka University Graduate School of Medicine, Osaka 565-0871, Japan
}

Correspondence should be addressed to Aya Nakae, anakae@anes.med.osaka-u.ac.jp

Received 13 September 2010; Accepted 19 December 2010

Academic Editor: Andrea Vecchione

Copyright ( $\odot 2011$ Aya Nakae et al. This is an open access article distributed under the Creative Commons Attribution License, which permits unrestricted use, distribution, and reproduction in any medium, provided the original work is properly cited.

Pain, which remains largely unsolved, is one of the most crucial problems for spinal cord injury patients. Due to sensory problems, as well as motor dysfunctions, spinal cord injury research has proven to be complex and difficult. Furthermore, many types of pain are associated with spinal cord injury, such as neuropathic, visceral, and musculoskeletal pain. Many animal models of spinal cord injury exist to emulate clinical situations, which could help to determine common mechanisms of pathology. However, results can be easily misunderstood and falsely interpreted. Therefore, it is important to fully understand the symptoms of human spinal cord injury, as well as the various spinal cord injury models and the possible pathologies. The present paper summarizes results from animal models of spinal cord injury, as well as the most effective use of these models.

\section{Introduction}

Spinal cord injury (SCI) often results in severe motor dysfunction, such as complete paralysis. These patients typically cannot only walk, but also lose bowel, bladder, and sexual functions. Pain impact following SCI has been reported as $37 \%$ of higher-level SCI patients with pain and $23 \%$ of lowerlevel SCI patients with pain; given the choice, these patients would trade pain relief for loss of bladder, bowel, or sexual functions [1]. Pain management is, therefore, an important health problem and topic of study.

Pain experiments with human subjects have proven to be practically challenging, fundamentally subjective, and ethically self-limiting. For these reasons, there remains a need for the use of laboratory animal models of pain. Pain is subjective in humans, and interpretation of animal model results requires careful attention. In fact, some have called for the abandonment of animal pain studies in favor of more extensive human testing.

A number of animal models of SCI exist and are primarily used to determine mechanisms of motor dysfunctions
[2-4]. Recently, these various SCI animal models have been utilized for pain studies [5]. However, when SCI animal models are used for pain research, special attention should be paid to the concomitant conditions. The present paper discussed the various SCI animal models as models for pain, with an emphasis on the complexities and limitations, as well as strategies for improvement and future use.

\section{Pain in SCI Patients}

2.1. SCI and the Social Impact. SCI occurs in most countries at an annual rate of 20-40 individuals per million. SCI is a devastating event that results in motor dysfunction below the level of lesion, as well as development of chronic pain syndromes. Studies have reported the prevalence of pain in SCI patients. A summary of results from 10 studies indicates that an average of $69 \%$ of the patients experienced pain, and nearly one-third of patients in pain rated their pain as severe [6]. The stakes are enormous, given the impact of pain on the economy (pain-related treatment costs 1 trillion US dollars 
per year in developed countries) [7]. If SCI pain could be eliminated, the quality of life could be greatly improved in patients; they would no longer suffer from pain and could take part in social aspects of life or earn money.

2.2. Spinal Cord Injury and Chronic Pain. Following mechanical injury to the spinal cord, a wave of secondary pathological changes occurs and amplifies the extent of initial damage. Apoptosis is critical for triggering collateral damage following primary injury to the spinal cord. Spontaneous and evoked pain is frequent in traumatic or ischemic spinal cord injury.

In complete and partial spinal lesions, chronic pain develops within months following injury [8]. Up to $80 \%$ of patients experience clinically significant pain, which is described as burning, stabbing, and/or electric-like $[9,10]$. Post-SCI pain results in drastically impaired daily routines and quality of life to a greater extent than motor impairment [11]; it is refractory to clinical treatments, despite a variety of neurosurgical, pharmacological, and behavioral therapeutic strategies $[12,13]$. The pain so greatly affects quality of life that depression and suicide frequently result $[14,15]$.

\section{Chronic Pain Classification in SCI (Tables 1 and 2)}

Siddall and colleagues [16] classified SCI pain from spinal cord injury into two broad types, with three regions of pain.

3.1. Nociceptive Pain. It is crucial for a pain clinician to distinguish between nociceptive or neuropathic pain, because the clinical approach for each is different. The first choice for nociceptive pain treatment following SCI is often a nonsteroidal, anti-inflammatory drug, or opiate, which often results in sufficient pain control.

3.1.1. Musculoskeletal Pain. Musculoskeletal pain is very common in SCI patients. In chronic states, secondary overuse or abnormal use of structures, such as the arm and shoulder, occurs [17]. Muscle spasm pain is a commonly observed type of musculoskeletal pain and is refractory for treatment of common musculoskeletal pain; analgesics are sometimes helpful, but antispasticity treatment may be needed in many cases [18].

3.1.2. Visceral Pain. Pathology in visceral structures, such as urinary tract infection, bowel impaction, and renal calculi, generally results in nociceptive pain. Visceral pain usually exhibits a delayed onset following SCI, which could be due to normal afferent input via sympathetic or vagal nerves in paraplegics or via the vagus nerve in tetraplegics $[19,20]$. Patients with upper thoracic injury or cervical SCI may present with autonomic dysreflexia headache, because of bowel impaction or bladder distension.

3.2. Neuropathic Pain. SCI often results in neuropathic pain, which is difficult to treat and exhibits various patterns due to its pathology.
Table 1: Classification of the Spinal Cord Injury Pain Task Force of the International Association of the Study of Pain.

\begin{tabular}{lll}
\hline Broad type & Broad system & Affected structures/Pathologies \\
\hline \multirow{2}{*}{ Nociceptive } & Musculoskeletal & Bone, joint, muscle trauma, or \\
& & inflammation \\
& Mechanical instability \\
& & Muscle spasm \\
& & Secondary overuse \\
& Visceral & Renal calculus (kidney stones) \\
& & Bowel and sphincter \\
& & dysfunctions \\
& & Headache by autonomic \\
& dysreflexia \\
\hline Neuropathic & Above-level & Compression mononeuropathy \\
& & Complex Regional Pain \\
& Syndrome \\
& At-level & Nerve root compression (cauda \\
& equine) \\
& Syringomyelia \\
& Spinal cord trauma/ischemia \\
& Dual-level cord and root \\
& trauma (double-lesion \\
& syndrome) \\
& Spinal cord trauma/ischemia \\
\hline &
\end{tabular}

TABLE 2: SCI pain classification by Bryce and Ragnarsson.

\begin{tabular}{lccl}
\hline Location & & Type & Etiologic subtypes \\
\hline Above-level & nociceptive & 1 & Mechanical and musculoskeletal \\
& & 2 & Autonomic dysreflexia headache \\
& & 3 & Others \\
& neuropathic & 4 & Compressive neuropathy \\
& & 5 & Others \\
\hline At-level & nociceptive & 6 & Mechanical and musculoskeletal \\
& & 7 & Visceral \\
& neuropathic & 8 & Central \\
& & 9 & Radiculopathy \\
& & 10 & Compressive neuropathy \\
& & 11 & Complex Regional Pain \\
& & & Syndrome \\
\hline Below-level & nociceptive & 12 & Mechanical and musculoskeletal \\
& & 13 & Visceral \\
& & & \\
& & & \\
& & 14 & Central \\
& & & Other \\
\hline
\end{tabular}

3.2.1. At-Level Pain. At-level pain occurs in dermatomes near the spinal injury and develops shortly after the injury. The pain is often characterized as stabbing or stimulusindependent and is accompanied by allodynia [21,22].

3.2.2. Below-Level Pain. Below-level pain is localized to dermatomes distal to the injury site and develops more gradually than at level pain; it is often classified as a stimulusindependent, continuous, burning pain $[21,22]$. 
3.2.3. Above-level Pain. Above-level pain occurs at dermatomes cranial to the injury site $[21,22]$.

3.3. Other Classification of SCI Pain (Table 2). Bryce et al. classified SCI pain by location of the pain [23]. In terms of animal behavior, this classification helps to provide a better understanding of pain pathology. In basic pain research, pain is defined as neuropathic or nociceptive. Similarly, SCI pain is complex and the pathology should be taken into consideration at the same time. It is important to understand the pathologies in each model.

\section{The Role of Animal Model}

Human self-ratings of pain, using questionnaires and scales, are reliable, accurate, and versatile for measuring experimental and clinical pain [24]. Nonetheless, the subjectivity of these measures has led to a decade-long search for surrogate biomarkers. To date, an objective surrogate with acceptable high sensitivity and specificity has not been identified. However, individual function-imaging scans could provide a reliable and objective measurement of subjective pain perception [25]. In addition, genetic biomarkers could prove to be useful. However, it is likely that too many genes are involved [26]. Moreover, genomic DNA variants could predict trait sensitivity to pain rather than ongoing levels of pain. Only a small percentage of injuries, infections, or others causes that results in chronic pain syndrome actually develop chronic pain. Therefore, in human studies, it will be difficult to determine the correlation between genetic background and pain severity. Furthermore, common clinical pain conditions, such as back pain, are too polygenic to be effectively modeled and genetically understood.

Animal models cannot self-report. In response to noxious stimuli, behaviors can be reliably and objectively scored, although these simple reflexes or innate responses (such as licking an inflamed paw) seem to lack clinical validity. Indeed, experiments with behavioral measurements of pain in animal models have become more common. According to studies published in flagship journals, pain studies comprise approximately $25 \%$ of total studies, more than any other field of study [27].

The animal model of pain plays a central role in analgesic drug development and the fundamental mechanisms that drive it. Despite the development of human imaging studies, such as functional MRI, the use of animal models of pain is a continuing necessity [5].

\section{Spinal Cord Injury Dynamics and Procedures}

Several models of neuropathic pain due to spinal cord injury have been simulated in rats. These studies have primarily focused on spinal cord injury caused by contusion or weight dropping, spinal cord compression, excitatory neurotoxins, photochemical-induced ischemia, spinal cord transaction, or crushing of the spinal cord. These models have also been adapted for mice [28-31]. The development of reliable neurotrauma mouse models provides great promise for evaluating overexpression or inactivation of certain genes on lesion pathophysiology and functional outcome. However, more attention should be focused on motor recovery while evaluating pain behavior, because of the delayed motor recovery in mice compared with rats $[32,33]$. The utility for each model summarizes in Table 3.

5.1. Contusive or Hemicontusive Models. Spinal contusion is the oldest and most widely used animal model. In addition to motor dysfunction, this injury elicits sensory dysfunction, including neuropathic pain, tactile allodynia, and thermal hyperalgesia $[34,35]$. Cervical contusion is rarely reported, because life-threatening adverse effects could occur. Therefore, cervical hemicontusion, following hemilaminectomy, is used to analyze the unilateral spinal cord contusion model. Because motor dysfunction appears in the forelimbs, painrelated behavior is difficult to estimate, and for this reason, cervical contusion is often utilized for motor functional analysis $[2,3]$. The thoracic spinal cord contusion model is the most popular pain research model and is induced with impactors, such as the weight-drop impactor [36]. In brief, the exposed spinal cord is injured by dropping a 10.0$\mathrm{g}$ rod from specified heights $[37,38]$. After 2 or 3 weeks, motor dysfunction is recovered and pain behavior can be analyzed. The impact of the injury tends to vary. Therefore, especially in short distances from the rod to spinal cord, pain behavior does not always appear. It is difficult to bilaterally drop the rod onto the spinal cord. Following injury, motor function analysis is needed to exclude unilateral paralysis and the possibility of unilateral contusion. Abnormal sensations due to mechanical, thermal, or cold stimuli are observed for several weeks or longer [32, 33, 39-52], and all regions (at-, above-, below-level) of allodynia are analyzed [53-56].

5.2. Transection or Hemisection Models. The complete spinal transection injury model reflects symptoms of complete SCI patients. Following laminectomy, spinal cord transection is performed with spring scissors. Occasionally, to attach the two ends for regeneration, a sterile, gel foam is placed between the two resected spinal cord ends. At-level and below-level neuropathic pains are then analyzed [57, 58]. Many studies have reported muscle spasms in the spinal complete transection model $[18,59,60]$, and musculoskeletal pain pathology during spasticity could help to clarify the use of this model.

The partial spinal transection injury model (hemisection) has become popular in neuropathic pain studies [6178]. Motor dysfunction appears only in the ipsilateral injured side and persists from 5 days to 4 weeks $[64,75]$. Mechanical allodynia and thermal hyperalgesia are bilaterally observed in above-level and below-level cases [61, 76-81].

5.3. Photochemical Model. Over the past two decades, the photochemical model of spinal cord injury, developed by Watson et al. [82], has proven to be one of the most reliable and reproducible graded experimental rat models of spinal cord injury [83-94] and has been widely used to study neurotrauma in mice [88]. The biggest advantage of 
TABLE 3: Animal spinal cord injury models and symptoms.

\begin{tabular}{|c|c|c|c|c|c|c|c|c|c|}
\hline \multirow{2}{*}{$\begin{array}{l}\text { Impact to } \\
\text { spinal cord }\end{array}$} & \multirow{2}{*}{$\begin{array}{l}\text { Laterality and } \\
\text { devices }\end{array}$} & & \multicolumn{2}{|l|}{ Injury area } & \multicolumn{3}{|c|}{ Sensory abnormality } & \multicolumn{2}{|l|}{ Duration } \\
\hline & & Cervical & Thoracic & Lumbar & At-level & Below-level & Above-level & Allodynia & $\begin{array}{l}\text { Maximal motor } \\
\text { dysfunction }\end{array}$ \\
\hline \multirow[t]{2}{*}{ Transection } & Bilateral & & 0 & o & 0 & 0 & $x$ & $\begin{array}{l}\text { Several weeks or } \\
\text { more }\end{array}$ & Less than 4 weeks \\
\hline & Unilateral & ○ & (-) & ○ & & (-) & ○ & $1-5$ weeks or more & $\begin{array}{l}\text { Ipsilateral to } \\
\text { injury: } 4 \text { weeks }\end{array}$ \\
\hline \multirow[t]{5}{*}{ Compression } & Contusion & & O & & O & ○ & O & Weeks to months & 1-2 weeks \\
\hline & Hemi-contusion & $n \quad 0$ & & & & & & & 3 weeks \\
\hline & Clip & & O & & O & $\begin{array}{l}\text { o: severe } \\
\text { injury } \\
\text { impossible }\end{array}$ & & 4 weeks & $\begin{array}{l}4 \text { weeks severe } \\
\text { injury }\end{array}$ \\
\hline & Displacement & & & & & ○) & & 4-6 weeks & 2 weeks \\
\hline & Canal stenosis & & & O & & o or $\times$ & & $\begin{array}{l}8 \text { days or } \\
\text { hypoalgesia }\end{array}$ & \\
\hline Photochemically & & & ○ & & ○ & & & 10-20 days & Various \\
\hline Excitotoxic & & & ○ & & O & ० & O? & 5 weeks or more & \\
\hline $\begin{array}{l}\text { Spinothalamic } \\
\text { tract lesions }\end{array}$ & & & ( & & (-) & & (0) & Several weeks & Less than 1week \\
\hline
\end{tabular}

Many spinal cord injury models exist for pain research. Pain behavior should not be measured in injured animals during maximal motor dysfunction.

this method is that the resulting injury does not induce mechanical trauma to the cord, because there is no need for laminectomy. Instead, an intravascular photochemical reaction occurs through the use of a dye that is activated by an argon ion laser to produce single oxygen molecules at the endothelial surface of spinal cord vessels. This results in an intense platelet response, as well as subsequent vessel occlusion and parenchymal tissue infarction [83]; the pathology is of a purely ischemic origin. Motor deficits are related to irradiation duration, as well as mechanical allodynia (cold, not thermal), which lasts for several days [91]. Following application of the von Frey filament to the trunk, behavioral analysis is performed according to vocalization threshold. Antiallodynic effects of analgesics have been determined using this model $[84,85,90]$. However, extent of injury is difficult to control. Therefore, motor deficit scores, such as BBB [95] and CBS [96], have been widely utilized [86, 90].

5.4. Excitotoxic Models. Intraspinal or intrathecally injection of some excitotoxins, such as quisqualic acid or other excitatory amino acids (glutamate, $\mathrm{N}$-methylasparate, and kainic acid), produces long-lasting spontaneous pain, mechanical allodynia, and thermal hyperalgesia in rats and mice [97, 98]. Following excitotoxin injections, neuronal loss, cavity formation, astrocytic scaring, and prominent inflammation occur. The advantage of this model is the ability to correlate specific areas of tissue damage with behavioral changes. Moreover, the percentage of animals that exhibit pain-related behaviors following injury is greater than with other models; induced mechanical allodynia was $67 \%$ in the contusion injury model [99], in contrast to $44 \%$ chronic allodynia following ischemic injury [86]. In excitotoxic animal models, nearly $100 \%$ animals develop varying degrees of hypersensitivity to mechanical and thermal stimuli [98].

\subsection{Other Mechanical Spinal Cord Injuries}

5.5.1. Clip Compression Injury. Clip compression injury resembles spinal contusion injury at the point of the injury caused by pressure to the spinal cord. Following laminectomy, compression injury is induced with clips calibrated to exert a force of 50 or $35 \mathrm{~g}$. The 50 -g clip induces severe injury and the 35-g clip induces moderate injury. Either clip is dorsoventrally closed over the entire cord for $1 \mathrm{~min}$ and then subsequently removed [58, 100-102]. A vascular clip is used for this procedure in mice [103]; the spinal cord becomes ischemic and mimics common clinical injuries and outcomes.

5.5.2. Spinal Cord Displacement. The spinal cord displacement model attempts to regulate trauma impact by controlling displacement length of the spinal cord. Through the use of this model, a cutoff for normal sensory function has been determined [104]. In human SCI, trauma severity is not proportional to pain severity, because the method of injury varies. The unique features of controlled displacement and monitoring of biomechanical parameters at the time of impact help to reduce outcome variability [105].

5.5.3. Canal Stenosis. Lumbar canal stenosis is due to entrapment of the cauda equine and/or lumber nerve roots by hypertrophy of osseous and soft tissue structures 
surrounding the lumbar spinal canal. A typical pathology is reduced blood flow to the peripheral nerve, resulting in demyelination or axonal degeneration, depending on the magnitude of ischemic injury. Canal stenosis can also be termed a spinal cord injury model, in which square-shaped pieces of silicon are placed into the epidural space in the rat $[106,107]$. However, these procedures also induce mechanical hypoalgesia [107]. Nevertheless, this model could help to clarify pathophysiology of chronic, light pressure to the spinal cord.

5.5.4. Spinothalamic Tract Lesions. The spinothalamic tract is the core pain pathway in the spinal cord. This model is designed to lesion only the spinothalamic tract area using a tungsten microelectrode. Although this model injures the unilateral spinothalamic tract, bilateral above- and below-level hyperalgesia, as well as allodynia, is induced and can persist for many weeks. These features resemble allodynia and hyperalgesia experienced by humans suffering from central pain syndromes following spinal cord injury. Therefore, this model could provide useful and novel insights into the underlying biological mechanisms of spinal cord injury [108].

\section{Pain-Related Behavior As an Evaluation of Symptoms}

Pain-related behavior is recorded using various devices applied to the forelimbs, hindlimbs, trunk, and face. If pain behavior appears in the face, it is considered to reflect the reaction to supraspinal mechanisms, because sensory function in the face is regulated by the trigeminal nerve (a cranial nerve). In thoracic spinal cord injury, trunk allodynia reflects at-level neuropathic pain, and allodynia in the hindlimb reflects below-level neuropathic pain. Forelimb allodynia reflects at-level neuropathic pain in cervical injury and above-level neuropathic pain in other injuries.

Abnormal pain behavior is a result of three different stimulations: mechanical, thermal, and cold.

6.1. Mechanical Allodynia. Mechanical allodynia can be measured in various ways using the von Frey hair. In one of the methods, the "up-down method" [109], each von Frey hair is applied to the test area for 2-3 s, with a 1-2-minute interval between stimuli. The trial begins with application of the $15-\mathrm{mN}$ von Frey probe to the hindpaws. A positive response is defined as a rapid withdrawal and/or licking of the paw immediately upon application of the stimulus. The von Frey hair can also be used to determine vocalization threshold to graded mechanical allodynia as a means to evaluate at-level neuropathic pain in the trunk [92]. When a positive response to stimulus occurs, the next smaller von Frey hair is applied. If a negative response occurs, the next higher force is applied. Testing continues for five or more stimuli after the first change in response, and the pattern of responses is converted to a 50\% von Frey threshold using a previously described technique [109]. If the animal shows no response to the highest von Frey hair $(160 \mathrm{mN})$, a von
Frey threshold of $260 \mathrm{mN}$, corresponding to the next $\log$ increment in potential von Frey probes, is assigned to the threshold.

Touch-evoked agitation is another evaluation of mechanical allodynia [110] and can be used to test the animal response to tactile stimulation. The animal skin is briskly stroked with a pencil point in a rostral to caudal direction. The animal response is graded with a score of 0 : no response, 1: moderate efforts to avoid the probe, transient vocalization, and 2: vigorous efforts to escape the stimulus, frequent and sustained vocalization in response to the probe.

Pathological reactions between the von Frey probe and pencil point vary due to reactions to the von Frey hair (caused by A-delta-fiber and C-fiber) or the pencil (A-beta fiber).

6.2. Thermal Hyperalgesia. Thermal hyperalgesia can be measured by latency of paw withdrawal in response to a radiant heat source [111]. Briefly, animals are placed in Plexiglas boxes on an elevated glass plate heated by a radiant heat source directed by a beam of light to the planter surface of each paw through the glass plate $\left(47^{\circ} \mathrm{C}\right)$. The light beam is automatically turned off by a photocell upon limb-lift, allowing for measurement of time between stimulus start and paw withdrawal (paw withdrawal latency). Three to five minutes are allowed between each trial, and three trials are averaged for each limb.

6.3. Cold Allodynia. Cold sensitivity to acetone can be quantified by foot withdrawal frequency [112]. A total of $100 \mu \mathrm{L}$ acetone is applied to the paw planter surface using a plastic tubule connected to a $1 \mathrm{ml}$ syringe. Acetone is applied 5 times to each paw at an interval of at least 5 minutes. The number of brisk foot withdrawals is recorded.

\section{Evaluation of Motor Functions in the Spinal Cord Injury Model}

Locomotor function is observed and recorded using the Basso, Beattie, and Bresnahan (BBB) Locomotor Rating Scale [95]. Briefly, the BBB is a 22-point ordinal scale ranging from 0 (no discernable hindlimb movement) to 21 (consistent and coordinated gait with parallel paw placement of the hindlimb and consistent trunk stability). Scores from 0 to 7 rank early phase of recovery, with return of isolated movements from three joints (hip, knee, and ankle); scores from 8 to 13 describe the intermediate recovery phase with, return of paw placement, stepping, and forelimb-hindlimb coordination; and scores from 14 to 21 represent late phase of recovery, with return of toe clearance during the step phase, predominant paw position, trunk stability, and tail position. Scores are tabulated and considered to be an indicator of motor recovery.

The Basso Mouse Scale (BMS), a 9-point rating scale, has been specially developed for mouse models [113]. An additional scoring systems, described by Gale et al. [96] and termed the Combined Behavioral Score (CBS) (Table 4), has been used to measure locomotor function. 
Following cervical spinal cord injury, recovery of forelimb function can be measured [114] by indicators such as the grooming test and forelimb asymmetry test [115]. Forelimb grooming function has been assessed using a scoring system originally developed to examine recovery in a rat brachial plexus reconstruction model [116]. The forelimb asymmetry, or paw preference test, is sensitive to asymmetries produced by a variety of CNS insults [117]. In addition, forelimb motor function recovery and pain behavior should be coanalyzed, because behavior is a result of motor functions [118].

\section{Future Direction and Conclusions}

8.1. Spinal Cord Injury As a Musculoskeletal Pain Model. Spinal cord injury leads to immediate impaired motor and sensory functions, which are also manifested over time. Following an initial period of spinal shock, reflexes become reduced and a disturbing hyperreflexia develops, which is often referred to as spasticity [119].

Spasticity is a disabling complication that affects individuals with spinal cord injury $[18,120]$. Approximately $75 \%$ of individuals with SCI exhibit spasticity 1 year after injury and half undergo antispasticity treatment [121]. Significant scientific interest has been devoted to spasticity over the past $10-15$ years as an example of plastic changes occurring distal to a central lesion.

The primary mechanisms hypothesized to be responsible for spasticity are increased motoneuron excitability [122, 123] and increased synaptic input, as a result of muscle stretch and reduced inhibitory mechanisms (presynaptic [124] and reciprocal inhibitions [125]). The mechanisms underlying decreased inhibition below the lesion remain poorly understood [59].

The most commonly proposed mechanisms to account for decreased inhibition following spinal cord injury include disruptions of facilitatory supraspinal input to inhibitory interneurons $[59,126]$. Motoneuron and sensory neurons are often regulated by common mechanisms [127], and common molecular mechanisms could be responsible for below-level neuropathic pain and spasticity $[18,37]$.

The spinal cord injury model, in particular the spinal transaction model, is considered useful for spasticity research. Because spasticity results in musculoskeletal pain, the spinal cord injury model could be considered a musculoskeletal pain model.

8.2. Spinal Cord Injury As a Visceral Pain Model. Visceral pain in spinal cord injury commonly triggers autonomic dysreflexia, a potentially life-threatening hypertensive syndrome due to high thoracic spinal cord injury. Pathology correlates with increased sprouting of primary afferent c-fibers into the spinal cord. During motor dysfunction, visceral painrelated behavior is difficult to analyze. However, based on the above-described mechanisms, a morphological approach to spinal complete transection injury has been utilized [128].
TABLE 4: Combined Behavioral Score (CBS), as reported by Gale et al. [96].

\begin{tabular}{|c|c|c|}
\hline $\begin{array}{l}\text { General } \\
\text { description }\end{array}$ & & Points \\
\hline \multicolumn{3}{|l|}{ Motor score } \\
\hline 0 & Normal walking & 0 \\
\hline 1 & Walks with mild deficit & 5 \\
\hline 2 & Hindlimb can support weight & 15 \\
\hline 3 & $\begin{array}{l}\text { Frequent movement of hindlimb, no } \\
\text { weight support }\end{array}$ & 25 \\
\hline 4 & $\begin{array}{l}\text { Minor movement in hindlimb, no } \\
\text { weight bearing }\end{array}$ & 40 \\
\hline 5 & $\begin{array}{l}\text { No movement in hindlimb, no weight } \\
\text { bearing }\end{array}$ & 45 \\
\hline \multicolumn{3}{|l|}{ Toe spread } \\
\hline 0 & Normal, full, toe spread & 0 \\
\hline 1 & Partial spreading of toes & 2.5 \\
\hline 2 & No spreading of toes & 5 \\
\hline \multicolumn{3}{|l|}{ Righting } \\
\hline 0 & $\begin{array}{l}\text { Normal righting, counter to direction } \\
\text { of roll }\end{array}$ & 0 \\
\hline 1 & Weakened attempt to right & 5 \\
\hline 2 & Delayed attempt to right & 10 \\
\hline 3 & Delayed attempt to right itself & 15 \\
\hline \multicolumn{3}{|l|}{$\begin{array}{l}\text { Extension } \\
\text { withdrawal }\end{array}$} \\
\hline 0 & Normal & 0 \\
\hline 1 & $\begin{array}{l}\text { Weak and slow reflex to withdraw } \\
\text { hindlimb }\end{array}$ & 2.5 \\
\hline 2 & No withdrawal reflex & 5 \\
\hline \multicolumn{3}{|l|}{ Placing } \\
\hline 0 & Normal placing & 0 \\
\hline 1 & Weak attempt to place foot & 2.5 \\
\hline 2 & No attempt to place foot & 5 \\
\hline \multicolumn{3}{|c|}{ Inclined plate } \\
\hline 0 & $65 \sim 70 /$ deg & 0 \\
\hline 1 & $55 \sim 60$ & 5 \\
\hline 2 & $40 \sim 50$ & 10 \\
\hline 3 & $<40$ & 15 \\
\hline
\end{tabular}

8.3. Limitations of Animal Models of Chronic Pain. Limited success in the pain field during the past few decades has resulted in a plethora of basic scientific data. The use of animal models has increased our knowledge of novel, effective, and safe clinical analgesics. Experimental failures with novel drugs are associated with adverse side effects and the lack of efficacy in humans. In addition, psychosocial aspects of chronic pain due to spinal cord injury have been completely omitted, despite a large body of knowledge emphasizing the importance of these factors in chronic pain. Future studies should extend the scope of inquiry to include the psychosocial aspects of chronic pain and spinal cord injury. 
8.4. Conclusion. By widening the number of animal models of spinal cord injury, new challenges have emerged. Although experimental methods of spinal cord injury pain lead to various behavioral outcomes, it is clear that some models respond similarly to pharmacological agents. This suggests that common mechanisms could underlie specific symptoms derived from various injury conditions. Etiologies of spinal cord injury pain could vary. However, by focusing on various symptoms of spinal cord injury pain, treatment possibilities for pathologies of spinal cord injury pain could emerge.

Continuous basic and clinical studies focused on different aspects of spinal cord injury pain are needed to better understand the mechanisms involved.

\section{References}

[1] C. Nepomuceno, P. R. Fine, J. S. Richards et al., "Pain in patients with spinal cord injury," Archives of Physical Medicine and Rehabilitation, vol. 60, no. 12, pp. 605-609, 1979.

[2] J. C. Gensel, C. A. Tovar, F. P. T. Hamers, R. J. Deibert, M. S. Beattie, and J. C. Bresnahan, "Behavioral and histological characterization of unilateral cervical spinal cord contusion injury in rats," Journal of Neurotrauma, vol. 23, no. 1, pp. 3654, 2006.

[3] V. J. Tom, H. R. Sandrow-Feinberg, K. Miller et al., "Combining peripheral nerve grafts and chondroitinase promotes functional axonal regeneration in the chronically injured spinal cord," The Journal of Neuroscience, vol. 29, no. 47, pp. 14881-14890, 2009.

[4] K. Sadlaoud, S. Tazerart, C. Brocard et al., "Differential plasticity of the GABAergic and glycinergic synaptic transmission to rat lumbar motoneurons after spinal cord injury," The Journal of Neuroscience, vol. 30, no. 9, pp. 3358-3369, 2010.

[5] J. S. Mogil, K. D. Davis, and S. W. Derbyshire, "The necessity of animal models in pain research," Pain, vol. 151, no. 1, pp. 12-17, 2010.

[6] J. J. Bonica, "Introduction: semantic, epidemiologic, and educational issues," in Pain and Central Nervous System Disease: The Central Pain Syndromes, pp. 13-29, Raven Press, New York, NY, USA, 1991.

[7] W. F. Stewart, J. A. Ricci, E. Chee, D. Morganstein, and R. Lipton, "Lost productive time and cost due to common pain conditions in the US workforce," Journal of the American Medical Association, vol. 290, no. 18, pp. 2443-2454, 2003.

[8] J. S. Richards, R. L. Meredith, C. Nepomuceno, P. R. Fine, and G. Bennett, "Psycho-social aspects of chronic pain in spinal cord injury," Pain, vol. 8, no. 3, pp. 355-366, 1980.

[9] N. B. Finnerup, I. L. Johannesen, S. H. Sindrup, F. W. Bach, and T. S. Jensen, "Pain and dysesthesia in patients with spinal cord injury: a postal survey," Spinal Cord, vol. 39, no. 5, pp. 256-262, 2001.

[10] P. J. Siddall, J. M. McClelland, S. B. Rutkowski, and M. J. Cousins, "A longitudinal study of the prevalence and characteristics of pain in the first 5 years following spinal cord injury," Pain, vol. 103, no. 3, pp. 249-257, 2003.

[11] D. H. Rintala, P. G. Loubser, J. Castro, K. A. Hart, and M. J. Fuhrer, "Chronic pain in a community-based sample of men with spinal cord injury: prevalence, severity, and relationship with impairment, disability, handicap, and subjective wellbeing," Archives of Physical Medicine and Rehabilitation, vol. 79, no. 6, pp. 604-614, 1998.
[12] T. E. Balazy, "Clinical management of chronic pain in spinal cord injury," Clinical Journal of Pain, vol. 8, no. 2, pp. 102110, 1992.

[13] J. A. Turner, D. D. Cardenas, C. A. Warms, and C. B. McClellan, "Chronic pain associated with spinal cord injuries: a community survey," Archives of Physical Medicine and Rehabilitation, vol. 82, no. 4, pp. 501-508, 2001.

[14] D. M. Cairns, R. H. Adkins, and M. D. Scott, "Pain and depression in acute traumatic spinal cord injury: origins of chronic problematic pain?" Archives of Physical Medicine and Rehabilitation, vol. 77, no. 4, pp. 329-335, 1996.

[15] M. Segatore, "Understanding chronic pain after spinal cord injury," The Journal of Neuroscience Nursing, vol. 26, no. 4, pp. 230-236, 1994.

[16] P. J. Siddall, R. P. Yezierski, and J. D. Loeser, "Pain following spinal cord injury: clinical features, prevalence, and taxonomy," IASP Newsletter, vol. 3, pp. 3-7, 2000.

[17] M. Dalyan, D. D. Cardenas, and B. Gerard, "Upper extremity pain after spinal cord injury," Spinal Cord, vol. 37, no. 3, pp. 191-195, 1999.

[18] K. C. Murray, A. Nakae, M. J. Stephens et al., "Recovery of motoneuron and locomotor function after spinal cord injury depends on constitutive activity in 5-HT receptors," Nature Medicine, vol. 16, no. 6, pp. 694-700, 2010.

[19] B. R. Komisaruk, C. A. Gerdes, and B. Whipple, "'Complete' spinal cord injury does not block perceptual responses to genital self-stimulation in women," Archives of Neurology, vol. 54, no. 12, pp. 1513-1520, 1997.

[20] R. A. Kuhn, "Functional capacity of the isolated human spinal cord," Brain, vol. 73, no. 1, pp. 1-51, 1950.

[21] P. J. Siddall, R. P. Yezierski, and J. D. Loeser, "Taxonomy and epidemiology of spinal cord injury pain," in Spinal Cord Injury Pain: Assessment, Mechanism, Management, Progress in Pain Research Management, R. P. Yesierski and K. J. Burchiel, Eds., vol. 23, pp. 9-24, IASP Press, Seattle, Wash, USA, 2002.

[22] C. J. Vierck Jr. and A. R. Light, "Allodynia and hyperalgesia within dermatomes caudal to a spinal cord injury in primates and rodents," in Nervous System Plasticity and Chronic Pain, J. Sandkuhler, B. Bromm, and G. Gebhart, Eds., vol. 129, pp. 411-428, Elsevier, Amsterdam, The Netherlands, 2000.

[23] T. N. Bryce, M. P. J. M. Dijkers, K. T. Ragnarsson, A. B. Stein, and B. Chen, "Reliability of the Bryce/Ragnarsson spinal cord injury pain taxonomy," The Journal of Spinal Cord Medicine, vol. 29, no. 2, pp. 118-132, 2006.

[24] D. D. Price, P. A. McGrath, A. Rafii, and B. Buckingham, "The validation of visual analogue scales as ratio scale measures for chronic and experimental pain," Pain, vol. 17, no. 1, pp. 4556, 1983.

[25] D. Borsook and L. Becerra, "Phenotyping central nervous system circuitry in chronic pain using functional MRI: considerations and potential implications in the clinic," Current Pain and Headache Reports, vol. 11, no. 3, pp. 201207, 2007.

[26] M. L. Lacroix-Fralish and J. S. Mogi, "Progress in genetic studies of pain and analgesia," Annual Review of Pharmacology and Toxicology, vol. 49, pp. 97-121, 2009.

[27] J. S. Mogil, K. Simmonds, and M. J. Simmonds, "Pain research from 1975 to 2007: a categorical and bibliometric meta-trend analysis of every research paper published in the journal, pin," Pain, vol. 142, no. 1-2, pp. 48-58, 2009.

[28] M. L. Starkey, M. Davies, P. K. Yip et al., "Expression of the regeneration-associated protein SPRR1A in primary sensory 
neurons and spinal cord of the adult mouse following peripheral and central injury," Journal of Comparative Neurology, vol. 513, no. 1, pp. 51-68, 2009.

[29] S. A. Marques, V. F. Garcez, E. A. Del Bel, and A. M. B. Martinez, "A simple, inexpensive and easily reproducible model of spinal cord injury in mice: morphological and functional assessment," Journal of Neuroscience Methods, vol. 177, no. 1, pp. 183-193, 2009.

[30] H. Kanno, H. Ozawa, A. Sekiguchi, and E. Itoi, "Spinal cord injury induces upregulation of Beclin 1 and promotes autophagic cell death," Neurobiology of Disease, vol. 33, no. 2, pp. 143-148, 2009.

[31] R. V. Ung, E. S. Landry, P. Rouleau, N. P. Lapointe, C. Rouillard, and P. A. Guertin, "Role of spinal 5-HT receptor subtypes in quipazine-induced hindlimb movements after a low-thoracic spinal cord transection," European Journal of Neuroscience, vol. 28, no. 11, pp. 2231-2242, 2008.

[32] E. L. Hoschouer, F. Q. Yin, and L. B. Jakeman, "L1 cell adhesion molecule is essential for the maintenance of hyperalgesia after spinal cord injury," Experimental Neurology, vol. 216, no. 1, pp. 22-34, 2009.

[33] B. J. Kerr and S. David, "Pain behaviors after spinal cord contusion injury in two commonly used mouse strains," Experimental Neurology, vol. 206, no. 2, pp. 240-247, 2007.

[34] M. Tanabe, K. Ono, M. Honda, and H. Ono, "Gabapentin and pregabalin ameliorate mechanical hypersensitivity after spinal cord injury in mice," European Journal of Pharmacology, vol. 609, no. 1-3, pp. 65-68, 2009.

[35] E. L. Hoschouer, F. Q. Yin, and L. B. Jakeman, "L1 cell adhesion molecule is essential for the maintenance of hyperalgesia after spinal cord injury," Experimental Neurology, vol. 216, no. 1, pp. 22-34, 2009.

[36] J. A. Gruner, "A monitored contusion model of spinal cord injury in the rat," Journal of Neurotrauma, vol. 9, no. 2, pp. 123-128, 1992.

[37] A. Nakae, K. Nakai, T. Tanaka et al., "Serotonin2C receptor mRNA editing in neuropathic pain model," Neuroscience Research, vol. 60, no. 2, pp. 228-231, 2008.

[38] E. D. Crown, Z. Ye, K. M. Johnson, G. Y. Xu, D. J. McAdoo, and C. E. Hulsebosch, "Increases in the activated forms of ERK 1/2, p38 MAPK, and CREB are correlated with the expression of at-level mechanical allodynia following spinal cord injury," Experimental Neurology, vol. 199, no. 2, pp. 397407, 2006

[39] J. G. Meisner, A. D. Marsh, and D. R. Marsh, "Loss of GABAergic interneurons in laminae I-III of the spinal cord dorsal horn contributes to reduced GABAergic tone and neuropathic pain after spinal cord injury," Journal of Neurotrauma, vol. 27, no. 4, pp. 729-737, 2010.

[40] E. L. Hoschouer, D. M. Basso, and L. B. Jakeman, "Aberrant sensory responses are dependent on lesion severity after spinal cord contusion injury in mice," Pain, vol. 148, no. 2, pp. 328-342, 2010.

[41] C. M. Mann, J. H. T. Lee, J. Hillyer, A. M. T. Stammers, W. Tetzlaff, and B. K. Kwon, "Lack of robust neurologic benefits with simvastatin or atorvastatin treatment after acute thoracic spinal cord contusion injury," Experimental Neurology, vol. 221, no. 2, pp. 285-295, 2010.

[42] S. M. Carlton, J. Du, H. Y. Tan et al., "Peripheral and central sensitization in remote spinal cord regions contribute to central neuropathic pain after spinal cord injury," Pain, vol. 147, no. 1-3, pp. 265-276, 2009.

[43] T. Furuya, M. Hashimoto, M. Koda et al., "Treatment of rat spinal cord injury with a Rho-kinase inhibitor and bone marrow stromal cell transplantation," Brain Research, vol. 1295, pp. 192-202, 2009.

[44] I. D. Hentall and S. B. Burns, "Restorative effects of stimulating medullary raphe after spinal cord injury," Journal of Rehabilitation Research \& Development, vol. 46, no. 1, pp. 109-122, 2009.

[45] M. A. Hook, G. Moreno, S. Woller et al., "Intrathecal morphine attenuates recovery of function after a spinal cord injury," Journal of Neurotrauma, vol. 26, no. 5, pp. 741-752, 2009.

[46] S. Lord-Fontaine, F. Yang, Q. Diep et al., "Local inhibition of Rho signaling by cell-permeable recombinant protein BA210 prevents secondary damage and promotes functional recovery following acute spinal cord injury," Journal of Neurotrauma, vol. 25, no. 11, pp. 1309-1322, 2008.

[47] A. M. Tan, S. Stamboulian, Y. W. Chang et al., "Neuropathic pain memory is maintained by Racl-regulated dendritic spine remodeling after spinal cord injury," The Journal of Neuroscience, vol. 28, no. 49, pp. 13173-13183, 2008.

[48] F. Knerlich-Lukoschus, M. Juraschek, U. Blömer, R. Lucius, H. M. Mehdorn, and J. Held-Feindt, "Force-dependent development of neuropathic central pain and time-related CCL2/CCR2 expression after graded spinal cord contusion injuries of the rat," Journal of Neurotrauma, vol. 25, no. 5, pp. 427-448, 2008.

[49] Y. Berrocal, D. D. Pearse, A. Singh et al., "Social and environmental enrichment improves sensory and motor recovery after severe contusive spinal cord injury in the rat," Journal of Neurotrauma, vol. 24, no. 11, pp. 1761-1772, 2007.

[50] J. Biernaskie, J. S. Sparling, J. Liu et al., "Skin-derived precursors generate myelinating Schwann cells that promote remyelination and functional recovery after contusion spinal cord injury," The Journal of Neuroscience, vol. 27, no. 36, pp. 9545-9559, 2007.

[51] M. G. Dombourian, N. A. Turner, T. A. Gerovac et al., "B1 and TRPV-1 receptor genes and their relationship to hyperalgesia following spinal cord injury," Spine, vol. 31, no. 24, pp. 2778-2782, 2006.

[52] C. D. Mills, J. J. Grady, and C. E. Hulsebosch, "Changes in exploratory behavior as a measure of chronic central pain following spinal cord injury," Journal of Neurotrauma, vol. 18, no. 10, pp. 1091-1105, 2001.

[53] C. H. Hubscher, J. D. Fell, and D. S. Gupta, "Sex and hormonal variations in the development of at-level allodynia in a rat chronic spinal cord injury model," Neuroscience Letters, vol. 477, no. 3, pp. 153-156, 2010.

[54] C. H. Hubscher, E. G. Kaddumi, and R. D. Johnson, "Segmental neuropathic pain does not develop in male rats with complete spinal transections," Journal of Neurotrauma, vol. 25, no. 10, pp. 1241-1245, 2008.

[55] J. Voda, A. Hama, and J. Sagen, "FK506 reduces the severity of cutaneous hypersensitivity in rats with a spinal cord contusion," Neuroscience Research, vol. 58, no. 1, pp. 95-99, 2007.

[56] B. C. Hains, J. P. Klein, C. Y. Saab, M. J. Craner, J. A. Black, and S. G. Waxman, "Upregulation of sodium channel Na1.3 and functional involvement in neuronal hyperexcitability associated with central neuropathic pain after spinal cord injury," The Journal of Neuroscience, vol. 23, no. 26, pp. 88818892, 2003.

[57] C. Scheifer, U. Hoheisel, P. Trudrung, T. Unger, and S. Mense, "Rats with chronic spinal cord transection as a possible model for the at-level pain of paraplegic patients," Neuroscience Letters, vol. 323, no. 2, pp. 117-120, 2002. 
[58] V. S. Densmore, A. Kalous, J. R. Keast, and P. B. Osborne, "Above-level mechanical hyperalgesia in rats develops after incomplete spinal cord injury but not after cord transection, and is reversed by amitriptyline, morphine and gabapentin," Pain, vol. 151, no. 1, pp. 184-193, 2010.

[59] C. Crone, N. T. Petersen, S. Gimenéz-Roldán, B. Lungholt, K. Nyborg, and J. B. Nielsen, "Reduced reciprocal inhibition is seen only in spastic limbs in patients with neurolathyrism," Experimental Brain Research, vol. 181, no. 1, pp. 193-197, 2007.

[60] S. A. Edgley and N. C. Aggelopoulos, "Short latency crossed inhibitory reflex actions evoked from cutaneous afferents," Experimental Brain Research, vol. 171, no. 4, pp. 541-550, 2006.

[61] A. D. Bennett, A. W. Everhart, and C. E. Hulsebosch, "Intrathecal administration of an NMDA or a non-NMDA receptor antagonist reduces mechanical but not thermal allodynia in a rodent model of chronic central pain after spinal cord injury," Brain Research, vol. 859, no. 1, pp. 72-82, 2000.

[62] M. D. Christensen, A. W. Everhart, J. T. Pickelman, and C. E. Hulsebosch, "Mechanical and thermal allodynia in chronic central pain following spinal cord injury," Pain, vol. 68, no. 1, pp. 97-107, 1996.

[63] B. C. Hains, K. M. Chastain, A. W. Everhart, D. J. McAdoo, and C. E. Hulsebosch, "Transplants of adrenal medullary chromaffin cells reduce forelimb and hindlimb allodynia in a rodent model of chronic central pain after spinal cord hemisection injury," Experimental Neurology, vol. 164, no. 2, pp. 426-437, 2000.

[64] M. F. Coronel, F. Labombarda, M. J. Villar, A. F. De Nicola, and S. L. González, "Progesterone prevents allodynia after experimental spinal cord injury," The Journal of Pain, vol. 12, no. 1, pp. 71-83, 2011.

[65] D. H. Roh, S. Y. Yoon, H. S. Seo et al., "Intrathecal injection of carbenoxolone, a gap junction decoupler, attenuates the induction of below-level neuropathic pain after spinal cord injury in rats," Experimental Neurology, vol. 224, no. 1, pp. 123-132, 2010.

[66] J. Kim, J. H. Kim, Y. Kim, H. Y. Cho, S. K. Hong, and Y. W. Yoon, "Role of spinal cholecystokinin in neuropathic pain after spinal cord hemisection in rats," Neuroscience Letters, vol. 462, no. 3, pp. 303-307, 2009.

[67] Y. S. Gwak and C. E. Hulsebosch, "Remote astrocytic and microglial activation modulates neuronal hyperexcitability and below-level neuropathic pain after spinal injury in rat," Neuroscience, vol. 161, no. 3, pp. 895-903, 2009.

[68] F. Marchand, C. Tsantoulas, D. Singh et al., "Effects of Etanercept and Minocycline in a rat model of spinal cord injury," European Journal of Pain, vol. 13, no. 7, pp. 673-681, 2009.

[69] Y. Lu, J. Zheng, L. Xiong, M. Zimmermann, and J. Yang, "Spinal cord injury-induced attenuation of GABAergic inhibition in spinal dorsal horn circuits is associated with downregulation of the chloride transporter KCC2 in rat," The Journal of Physiology, vol. 586, no. 23, pp. 5701-5715, 2008.

[70] F. Labombarda, M. F. Coronel, M. J. Villar, A. F. D. Nicola, and S. L. González, "Neuropathic pain and temporal expression of preprodynorphin, protein kinase $\mathrm{C}$ and $\mathrm{N}$-methyl-d-aspartate receptor subunits after spinal cord injury," Neuroscience Letters, vol. 447, no. 2-3, pp. 115-119, 2008.

[71] W. Liu, Z. Liu, LI. Liu et al., "A novel human foamy virus mediated gene transfer of GAD67 reduces neuropathic pain following spinal cord injury," Neuroscience Letters, vol. 432, no. 1, pp. 13-18, 2008.

[72] N. E. Saadé, H. A. Amin, S. Chalouhi, S. A. Baki, S. J. Jabbur, and S. F. Atweh, "Spinal pathways involved in supraspinal modulation of neuropathic manifestations in rats," Pain, vol. 126, no. 1-3, pp. 280-293, 2006.

[73] X. M. Peng, Z. G. Zhou, J. C. Glorioso, D. J. Fink, and M. Mata, "Tumor necrosis factor- $\alpha$ contributes to belowlevel neuropathic pain after spinal cord injury," Annals of Neurology, vol. 59, no. 5, pp. 843-851, 2006.

[74] J. Kim, Y. W. Yoon, S. K. Hong, and H. S. Na, "Cold and mechanical allodynia in both hindpaws and tail following thoracic spinal cord hemisection in rats: time courses and their correlates," Neuroscience Letters, vol. 343, no. 3, pp. 200204, 2003.

[75] B. C. Hains, K. M. Johnson, M. J. Eaton, W. D. Willis, and C. E. Hulsebosch, "Serotonergic neural precursor cell grafts attenuate bilateral hyperexcitability of dorsal horn neurons after spinal hemisection in rat," Neuroscience, vol. 116, no. 4, pp. 1097-1110, 2003.

[76] B. C. Hains, K. M. Chastain, A. W. Everhart, D. J. McAdoo, and C. E. Hulsebosch, "Transplants of adrenal medullary chromaffin cells reduce forelimb and hindlimb allodynia in a rodent model of chronic central pain after spinal cord hemisection injury," Experimental Neurology, vol. 164, no. 2, pp. 426-437, 2000.

[77] Y. S. Gwak, B. C. Hains, K. M. Johnson, and C. E. Hulsebosch, "Effect of age at time of spinal cord injury on behavioral outcomes in rat," Journal of Neurotrauma, vol. 21, no. 8, pp. 983-993, 2004.

[78] C. D. Mills, B. C. Hains, K. M. Johnson, and C. E. Hulsebosch, "Strain and model differences in behavioral outcomes after spinal cord injury in rat," Journal of Neurotrauma, vol. 18, no. 8, pp. 743-756, 2001.

[79] J. H.T. Lee, S. Tigchelaar, J. Liu et al., "Lack of neuroprotective effects of simvastatin and minocycline in a model of cervical spinal cord injury," Experimental Neurology, vol. 225, no. 1, pp. 219-230, 2010.

[80] J. Kim, J. I. Jung, H. S. Na, S. K. Hong, and Y. W. Yoon, "Effects of morphine on mechanical allodynia in a rat model of central neuropathic pain," NeuroReport, vol. 14, no. 7, pp. 1017-1020, 2003.

[81] B. C. Hains, K. M. Johnson, D. J. McAdoo, M. J. Eaton, and C. E. Hulsebosch, "Engraftment of serotonergic precursors enhances locomotor function and attenuates chronic central pain behavior following spinal hemisection injury in the rat," Experimental Neurology, vol. 171, no. 2, pp. 361-378, 2001.

[82] B. D. Watson, R. Prado, and W. D. Dietrich, "Photochemically induced spinal cord injury in the rat," Brain Research, vol. 367, no. 1-2, pp. 296-300, 1986.

[83] J. X. Hao, X. J. Xu, H. Aldskogius, A. Seiger, and Z. Wiesenfeld-Hallin, "The excitatory amino acid receptor antagonist MK-801 prevents the hypersensitivity induced by spinal cord ischemia in the rat," Experimental Neurology, vol. 113, no. 2, pp. 182-191, 1991.

[84] J. X. Hao, X. J. Xu, H. Aldskogius, A. Seiger, and Z. Wiesenfeld-Hallin, "Allodynia-like effects in rat after ischaemic spinal cord injury photochemically induced by laser irradiation," Pain, vol. 45, no. 2, pp. 175-185, 1991.

[85] H. K. Erichsen, J. X. Hao, X. J. Xu, and G. Blackburn-Munro, "Comparative actions of the opioid analgesics morphine, methadone and codeine in rat models of peripheral and central neuropathic pain," Pain, vol. 116, no. 3, pp. 347-358, 2005. 
[86] X. J. Xu, J. X. Hao, H. Aldskogius, A. Seiger, and Z. Wiesenfeld-Hallin, "Chronic pain-related syndrome in rats after ischemic spinal cord lesion: a possible animal model for pain in patients with spinal cord injury," Pain, vol. 48, no. 2, pp. 279-290, 1992.

[87] R. Prado, W. D. Dietrich, B. D. Watson, M. D. Ginsberg, and B. A. Green, "Photochemically induced graded spinal cord infarction. Behavioral, electrophysiological, and morphological correlates," Journal of Neurosurgery, vol. 67, no. 5, pp. 745-753, 1987.

[88] M. Gaviria, H. Haton, F. Sandillon, and A. Privat, "A mouse model of acute ischemic spinal cord injury," Journal of Neurotrauma, vol. 19, no. 2, pp. 205-221, 2002.

[89] J. X. Hao, T. Stöhr, N. Selve, Z. Wiesenfeld-Hallin, and X. J. $\mathrm{Xu}$, "Lacosamide, a new anti-epileptic, alleviates neuropathic pain-like behaviors in rat models of spinal cord or trigeminal nerve injury," European Journal of Pharmacology, vol. 553, no. 1-3, pp. 135-140, 2006.

[90] M. von Heijne, J. X. Hao, A. Sollevi, and X. J. Xu, "Effects of intrathecal morphine, baclofen, clonidine and R-PIA on the acute allodynia-like behaviours after spinal cord ischaemia in rats," European Journal of Pain, vol. 5, no. 1, pp. 1-10, 2001.

[91] J. X. Hao, X. J. Xu, H. Aldskogius, A. Seiger, and Z. Wiesenfeld-Hallin, "Photochemically induced transient spinal ischemia induces behavioral hypersensitivity to mechanical and cold stimuli, but not to noxious-heat stimuli, in the rat," Experimental Neurology, vol. 118, no. 2, pp. 187194, 1992.

[92] W. P. Wu, J. X. Hao, X. J. Xu, Z. Wiesenfeld-Hallin, W. Koek, and F. C. Colpaert, "The very-high-efficacy 5-HT receptor agonist, F 13640, preempts the development of allodynia-like behaviors in rats with spinal cord injury," European Journal of Pharmacology, vol. 478, no. 2-3, pp. 131-137, 2003.

[93] J. X. Hao, X. J. Xu, Y. X. Yu, A. Seiger, and Z. WiesenfeldHallin, "Transient spinal cord ischemia induces temporary hypersensitivity of dorsal horn wide dynamic range neurons to myelinated, but not unmyelinated, fiber input," Journal of Neurophysiology, vol. 68, no. 2, pp. 384-391, 1992.

[94] J. X. Hao, X. J. Xu, Y. X. Yu, A. Seiger, and Z. WiesenfeldHallin, "Hypersensitivity of dorsal horn wide dynamic range neurons to cutaneous mechanical stimuli after transient spinal cord ischemia in the rat," Neuroscience Letters, vol. 128, no. 1, pp. 105-108, 1991.

[95] D. M. Basso, M. S. Beattie, and J. C. Bresnahan, "A sensitive and reliable locomotor rating scale for open field testing in rats," Journal of Neurotrauma, vol. 12, no. 1, pp. 1-21, 1995.

[96] K. Gale, H. Kerasidis, and J. R. Wrathall, "Spinal cord contusion in the rat: behavioral analysis of functional neurologic impairment," Experimental Neurology, vol. 88, no. 1, pp. 123134, 1985.

[97] C. A. Fairbanks, K. L. Schreiber, K. L. Brewer et al., "Agmatine reverses pain induced by inflammation, neuropathy, and spinal cord injury," Proceedings of the National Academy of Sciences of the United States of America, vol. 97, no. 19, pp. 10584-10589, 2000.

[98] R. P. Yezierski, S. Liu, G. L. Ruenes, K. J. Kajander, and K. L. Brewer, "Excitotoxic spinal cord injury: behavioral and morphological characteristics of a central pain model," Pain, vol. 75, no. 1, pp. 141-155, 1998.

[99] P. Siddall, C. L. Xu, and M. Cousins, "Allodynia following traumatic spinal cord injury in the rat," NeuroReport, vol. 6, no. 9, pp. 1241-1244, 1995.

[100] M. G. Fehlings and C. H. Tator, "The relationships among the severity of spinal cord injury, residual neurological function, axon counts, and counts of retrogradely labeled neurons after experimental spinal cord injury," Experimental Neurology, vol. 132, no. 2, pp. 220-228, 1995.

[101] R. Nashmi and M. G. Fehlings, "Changes in axonal physiology and morphology after chronic compressive injury of the rat thoracic spinal cord," Neuroscience, vol. 104, no. 1, pp. 235-251, 2001.

[102] J. C. Bruce, M. A. Oatway, and L. C. Weaver, "Chronic pain after clip-compression injury of the rat spinal cord," Experimental Neurology, vol. 178, no. 1, pp. 33-48, 2002.

[103] S. A. Marques, V. F. Garcez, E. A. Del Bel, and A. M.B. Martinez, "A simple, inexpensive and easily reproducible model of spinal cord injury in mice: morphological and functional assessment," Journal of Neuroscience Methods, vol. 177, no. 1, pp. 183-193, 2009.

[104] A. D. Kloos, L. C. Fisher, M. R. Detloff, D. L. Hassenzahl, and D. M. Basso, "Stepwise motor and all-or-none sensory recovery is associated with nonlinear sparing after incremental spinal cord injury in rats," Experimental Neurology, vol. 191, no. 2, pp. 251-265, 2005.

[105] L. B. Jakeman, Z. Guan, W. Ping et al., "Traumatic spinal cord injury produced by controlled contusion in mouse," Journal of Neurotrauma, vol. 17, no. 4, pp. 299-319, 2000.

[106] T. Ito, S. Ohtori, G. Inoue et al., "Glial phosphorylated p38 MAP kinase mediates pain in a rat model of lumbar disc herniation and induces motor dysfunction in a rat model of lumbar spinal canal stenosis," Spine, vol. 32, no. 2, pp. 159167, 2007.

[107] M. Sekiguchi, S. Kikuchi, and R. R. Myers, "Experimental spinal stenosis: relationship between degree of cauda equina compression, neuropathology, and pain," Spine, vol. 29, no. 10, pp. 1105-1111, 2004.

[108] G. Wang and S. M. Thompson, "Maladaptive homeostatic plasticity in a rodent model of central pain syndrome: thalamic hyperexcitability after spinothalamic tract lesions," The Journal of Neuroscience, vol. 28, no. 46, pp. 11959-11969, 2008.

[109] S. R. Chaplan, F. W. Bach, J. W. Pogrel, J. M. Chung, and T. L. Yaksh, "Quantitative assessment of tactile allodynia in the rat paw," Journal of Neuroscience Methods, vol. 53, no. 1, pp. 55-63, 1994.

[110] T. L. Yaksh, "Behavioral and autonomic correlates of the tactile evoked allodynia produced by spinal glycine inhibition: effects of modulatory receptor systems and excitatory amino acid antagonists," Pain, vol. 37, no. 1, pp. 111-123, 1989.

[111] G. J. Bennett and Y. K. Xie, "A peripheral mononeuropathy in rat that produces disorders of pain sensation like those seen in man," Pain, vol. 33, no. 1, pp. 87-107, 1988.

[112] Y. Choi, Y. W. Yoon, H. S. Na, S. H. Kim, and J. M. Chung, "Behavioral signs of ongoing pain and cold allodynia in a rat model of neuropathic pain,” Pain, vol. 59, no. 3, pp. 369-376, 1994.

[113] D. M. Basso, L. C. Fisher, A. J. Anderson, L. B. Jakeman, D. M. McTigue, and P. G. Popovich, "Basso mouse scale for locomotion detects differences in recovery after spinal cord injury in five common mouse strains," Journal of Neurotrauma, vol. 23, no. 5, pp. 635-659, 2006.

[114] M. Martinez, J. M. Brezun, L. Bonnier, and C. Xerri, "A new rating scale for open-field evaluation of behavioral recovery after cervical spinal cord injury in rats," Journal of Neurotrauma, vol. 26, no. 7, pp. 1043-1053, 2009.

[115] J. C. Gensel, C. A. Tovar, F. P. T. Hamers, R. J. Deibert, M. S. Beattie, and J. C. Bresnahan, "Behavioral and histological characterization of unilateral cervical spinal cord contusion 
injury in rats," Journal of Neurotrauma, vol. 23, no. 1, pp. 36$54,2006$.

[116] J. A. Bertelli and J.-C. Mira, "Behavioral evaluating methods in the objective clinical assessment of motor function after experimental brachial plexus reconstruction in the rat," Journal of Neuroscience Methods, vol. 46, no. 3, pp. 203-208, 1993.

[117] Y. Liu, D. Kim, B. T. Himes et al., “Transplants of fibroblasts genetically modified to express BDNF promote regeneration of adult rat rubrospinal axons and recovery of forelimb function," The Journal of Neuroscience, vol. 19, no. 11, pp. 4370-4387, 1999.

[118] A. A. Webb and G. D. Muir, "Sensorimotor behaviour following incomplete cervical spinal cord injury in the rat," Behavioural Brain Research, vol. 165, no. 2, pp. 147-159, 2005.

[119] J. F. Ditunno, J. W. Little, A. Tessler, and A. S. Burns, "Spinal shock revisited: a four-phase model," Spinal Cord, vol. 42, no. 7, pp. 383-395, 2004.

[120] F. Biering-Sørensen, J. B. Nielsen, and K. Klinge, "Spasticityassessment: a review," Spinal Cord, vol. 44, no. 12, pp. 708 $722,2006$.

[121] F. M. Maynard, R. S. Karunas, and W. P. Waring III, "Epidemiology of spasticity following traumatic spinal cord injury," Archives of Physical Medicine and Rehabilitation, vol. 71, no. 8, pp. 566-569, 1990.

[122] P. Boulenguez and L. Vinay, "Strategies to restore motor functions after spinal cord injury," Current Opinion in Neurobiology, vol. 19, no. 6, pp. 587-600, 2009.

[123] Y. Li, M. A. Gorassini, and D. J. Bennett, "Role of persistent sodium and calcium currents in motoneuron firing and spasticity in chronic spinal rats," Journal of Neurophysiology, vol. 91, no. 2, pp. 767-783, 2004.

[124] R. Katz, "Presynaptic inhibition in humans: a comparison between normal and spastic patients," Journal of Physiology, vol. 93, no. 4, pp. 379-385, 1999.

[125] G. I. Boorman, R. G. Lee, W. J. Becker, and U. R. Windhorst, "Impaired "natural reciprocal inhibition" in patients with spasticity due to incomplete spinal cord injury," Electroencephalography and Clinical Neurophysiology, vol. 101, no. 2, pp. 84-92, 1996.

[126] S. A. Edgley and N. C. Aggelopoulos, "Short latency crossed inhibitory reflex actions evoked from cutaneous afferents," Experimental Brain Research, vol. 171, no. 4, pp. 541-550, 2006.

[127] P. Boulenguez, S. Liabeuf, R. Bos et al., "Down-regulation of the potassium-chloride cotransporter KCC2 contributes to spasticity after spinal cord injury," Nature Medicine, vol. 16, no. 3, pp. 302-307, 2010.

[128] S. Hou, H. Duale, and A. G. Rabchevsky, "Intraspinal sprouting of unmyelinated pelvic afferents after complete spinal cord injury is correlated with autonomic dysreflexia induced by visceral pain," Neuroscience, vol. 159, no. 1, pp. 369-379, 2009. 


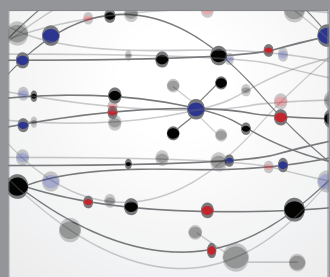

The Scientific World Journal
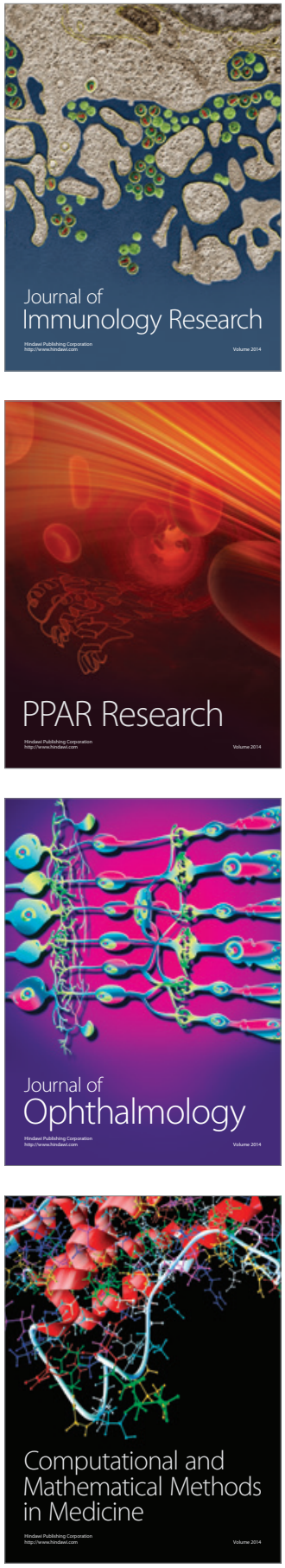

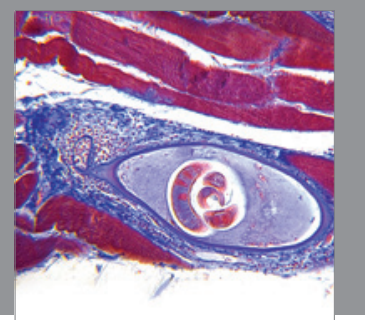

Gastroenterology

Research and Practice
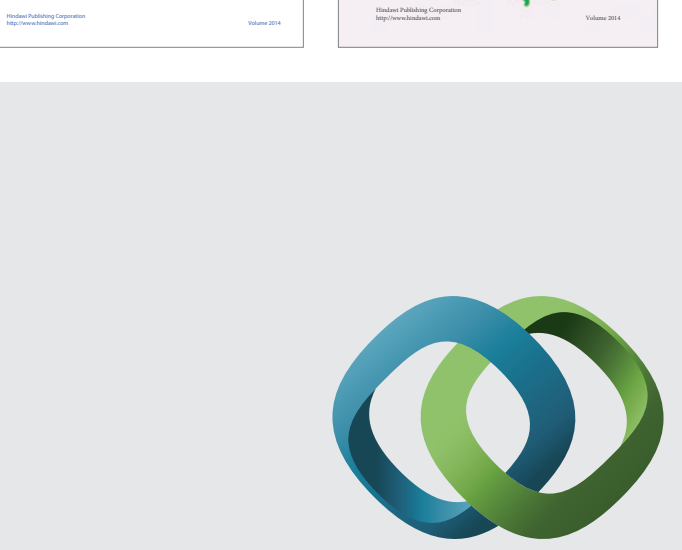

\section{Hindawi}

Submit your manuscripts at

http://www.hindawi.com
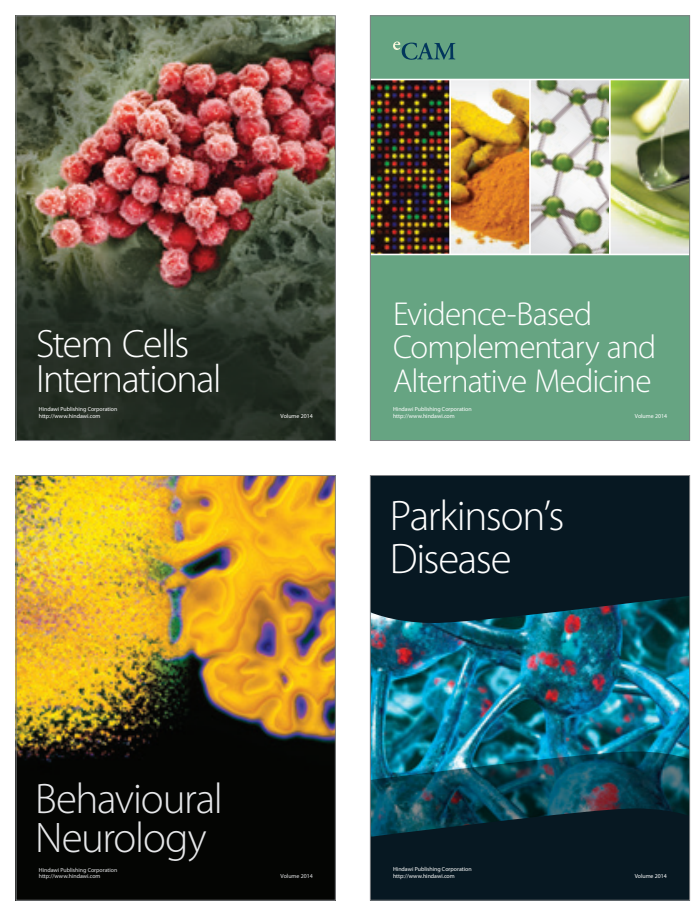

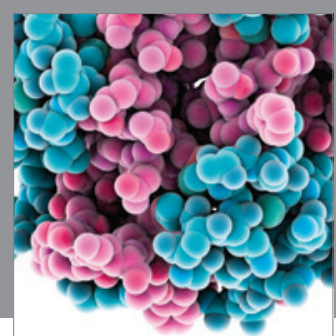

Journal of
Diabetes Research

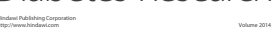

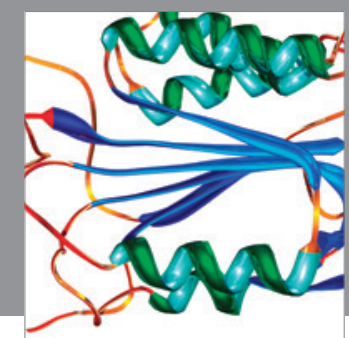

Disease Markers
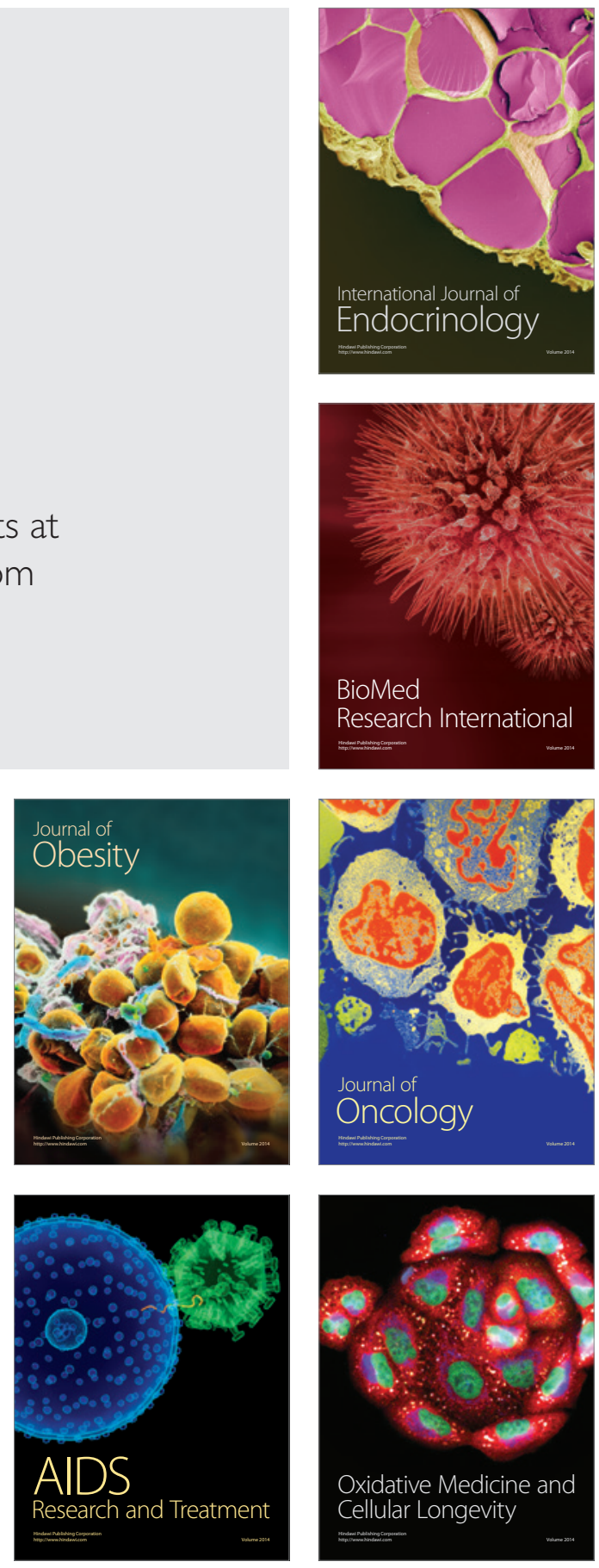